\title{
ALFABETIZAÇÃO NO MEIO RURAL E POLÍTICAS PÚBLICAS EDUCACIONAIS
}

\author{
LITERACY IN THE RURAL ENVIRONMENT AND PUBLIC EDUCATIONAL POLICIES
}

\author{
Arlete Lopes da Silva \\ Universidad de Desarrollo Sustentable, Asunción, Paraguai. E-mail: revista@gmail.com
}

DOI: https://doi.org/10.46550/amormundi.v2i4.114

Recebido em: 22.05.2021

Aceito em: 26.06.2021

\begin{abstract}
Resumo: $\mathrm{O}$ artigo reflete sobre a relação entre educação rural e políticas públicas educacionais. No primeiro momento apresenta o cenário da Educação rural no contexto geral do Brasil, bem como reflete acerca dos conceitos de Educação rural. Posteriormente, analisa as políticas públicas voltadas para educação rural e o analfabetismo rural, os desafios encontrados na educação do campo, sabendo que, se na educação urbana já são altos os desafios, bem mais são em uma escola com poucos recursos pedagógicos e tecnológicos.
\end{abstract}

Palavras-chave: Políticas Educacionais. Educação Rural. Analfabetismo Rural.

Abstract: The article reflects on rural education and educational public policies. At first, it presents the scenario of rural education in the general context of Brazil, as well as reflecting on the concepts of rural education. Subsequently, it analyzes public policies aimed at rural education and rural illiteracy and the challenges encountered in rural education, knowing that in urban education the challenges we imagine are high then in a school with few pedagogical and technological resources.

Keywords: Educational Policies. Rural Education. Rural Illiteracy.

\section{Introduçáo}

Brasil é o $5^{\circ}$ maior país do mundo e dividido em regiôes que foram colonizadas por
diferentes populaçóes, as quais trouxeram para nossa terra suas bagagens culturais, o que deu a nossa pátria um grande multiculturalismo e devido a essa enorme expansão territorial e a essas multiculturas, como também, devido as desigualdades sociais e econômicas entre as regiôes brasileiras, são notadas inúmeras diferenças na estrutura de ensino.

O acesso à educação na zona rural, embora tenha evoluído bastante no decorrer do tempo, ainda apresenta grandes problemáticas, em especial, no que se refere a mobilidade, a informaçáo e ao acesso a conteúdo e disciplinas necessários para o bom desenvolvimento escolar.

Mas quais seriam essas problemáticas? Quais as causas para que as mesmas ainda sejam encontradas na zona rural? Como a sociedade e a comunidade escolar avaliam as açóes governamentais em suas localidades? Quais as saídas que os professores têm utilizado para levar o incentivo à pesquisa mesmo com tantas dificuldades e faltas de ferramentas. 
Diante dessas indagaçóes, iremos abordar algumas temáticas que irão facilitar a compreensão do estudo. Tópicos esses que são: as políticas públicas na Educação Básica; as políticas Públicas voltadas para Educação Rural; e alfabetização Rural no Brasil

\section{Revisão de literatura}

\subsection{As Políticas Públicas na organização da Educação Básica}

Políticas públicas são tudo aquilo que faz ou deixa de fazer, sendo assim, políticas públicas educacionais é tudo aquilo que o governo faz ou deixa de fazer na educação. Dessa forma, pode se dizer que políticas públicas educacionais dizem respeito à educação escolar.

A educação além de se constituir a um direito social se refere se a um bem simbólico onde abrange a economia e a vida social, ou seja, a busca da educação vem crescendo com o intuito de acesso ao trabalho de qualidade e uma boa circulação social. Desta forma, as políticas públicas educacionais trazem os direitos e deveres que o cidadão tem diante da rede de ensino.

No art. 208 encontramos o compromisso do Estado com o provimento dessa educação:

O dever do Estado com a educação será efetivado mediante a garantia de :

I - educação básica obrigatória e gratuita dos 4 aos 17 anos de idade, assegurada inclusive sua oferta gratuita para todos os que a ela náo tiveram acesso na idade própria;

II - progressiva universalização do ensino médio gratuito;

$\$ 1^{\circ} \mathrm{O}$ acesso ao ensino obrigatório e gratuito é direito público subjetivo.

$\$ 2^{\circ} \mathrm{O}$ não oferecimento do ensino obrigatório pelo Poder Público, ou sua oferta ir regular, importa responsabilidade da autoridade competente.

Diante disso, pode se dizer que este foi um dos primeiros artigos e laborados para enfatizar os direitos dos cidadãos como sendo dever do Estado a educação a todos, citando assim as de vidas responsabilidades e penalidades caso não sejam atendidas essas medidas.

Quando se fala em Políticas Públicas na educação a abordagem trata - se da articulação de projetos que envolvem o Estado e a sociedade, na busca pela construção de uma educação mais inclusiva e de melhor qualidade, o u seja, que resgate a construção da cidadania (GIRON, 2008).

Desta forma, políticas públicas educacionais se refere as decisóes do governo que têm incidência no ambiente escolar enquanto ambiente de ensino - aprendizagem.

Tais decisões envolvem: construção do prédio, contratação de profissionais, formação docente, carreira, valorização profissional, matriz curricular, gestão escolar, entre outros.

Sendo assim, as políticas públicas educacionais além abordar sobre o acesso de todas as crianças e adolescentes as escolas públicas ela também é responsável pela construção da sociedade perante essas escolas através da educação.

As escolas no Brasil vêm buscando a qualidade da educação e oportunidades no ambiente escolar de maneira que o aluno se inclua na sociedade de forma positiva.

Porém, diante de um ensino de qualidade a educação pública necessita de docentes preparados e conscientes do seu papel educacional para que esse processo seja realizado com sucesso, dando assim a criança a oportunidade da construção do conhecimento através do 
aprendizado.

Direito de todos, dever da família e do ESTADO, inspirada nos princípios de liberdade e nos ideais de solidariedade humana, de valorização profissional, e gestão democrática do ensino público, a Educação, tal como definida na Lei de Diretrizes de Bases - LDB (Lei n.9.394/1996) e na $\mathrm{CF} / 88$, tem por finalidade o pleno desenvolvimento do educando, seu preparo para o exercício da cidadania e sua qualificação para o mundo do trabalho.

O formato assumido pela Política de Educação no Brasil atualmente resulta dos debates travados durante os longos anos em que foram traçadas as suas diretrizes e bases, em especial no período após a $\mathrm{CF} / 88$.

Os dois principais aspectos em debates na construção da Lei de Diretrizes e Bases da Educação foram.

A necessidade de universalização do ensino básico, haja vista as desigualdades sociais e regionais no tocante ao acesso e a permanência no ensino fundamental, expressadas pelos altos índices de analfabetismo e de evasão.

A necessidade de redefinição das estratégias de Educação para atender as exigências impostas pelos impactos da globalização.

No último levantamento feito pelo IBGE, Perfil dos Municípios Brasileiros, constatouse que somente 2.898 municípios possuem um sistema municipal de ensino próprio. Contudo, mesmo com indicadores que demonstram poucos avanços frente ao aparelhamento educacional dos municípios, a pesquisa também verificou que 3.138 municípios possuem um Plano Municipal de Educação.

Tal informação e lúcida a importância do planejamento e do desenvolvimento de açóes voltadas para a educação básica que, muitos casos, ficam sob a responsabilidade municipal.

Assim como a saúde e a assistência social, a Educação integra o conjunto dos direitos sociais estabelecidos no artigo $6^{\circ}$. Ela e um direito de todos, um dever do Estado a da família (Art.204) e deverá ser gratuita quando prestada nos estabelecimentos oficiais (Art.206).

Ao detalhar a forma como a educação será efetiva pelo Estado, a CF/88 define, entre outras questóes, que:

- O ensino fundamental é obrigatório e gratuito, inclusive para os que a ele não tiverem acesso na idade própria, o que é um grande avanço em relação às constituiçóes federais anteriores.

- O ensino médio também de ver a ser gratuito.

- $\mathrm{O}$ atendimento educacional especializado às pessoas com deficiência deverá ser prestado preferencialmente na rede regular de ensino.

- O direito à educação básica estende - se ao atendimento em creche e pré-escola as crianças de zero a seis a nos de idade.

- O direito de acesso aos níveis mais elevados do ensino, da pesquisa e da criação artística segundo a capacidade de cada um.

- O direito ao ensino no turno regular adequado as condiçóes do educando.

- O direito ao atendimento do educando no ensino fundamental, através de programas suplementares de material didático escolar, transporte, alimentação e assistência à saúde prescrição esta de fundamental importância para parcelas significativas do alunado, pois tais 
serviços são pré-requisitos para a frequência escolar. Conforme o Ar t.21 da LDB, a educação escolar compóe - se de : a Educação Básica; - Educação Superior; Educação de Jovens e Adultos (EJA); Educação Profissional; Ensino fundamental obrigatório e gratuito, assegurando-se igual acesso para todos os que a ele não tiveram oportunidade na idade própria.

O não oferecimento do ensino obrigatório pelo Poder Público ou a oferta irregular para a faixa que compreende dos 6 aos 14 anos importa a responsabilidade da autoridade competente (cf. do Artigo 208 da CF /88). isso significa que se pode responsabilizar, pessoal e diretamente, a autoridade incumbida da oferta desse direito e não apenas o Poder Público em geral.

Nesse sentido, é de responsabilidade do Poder Público local o recenseamento dos educandos no ensino fundamental, zelando por sua frequência à escola.

Ressalta-se aqui o importante papel dos Conselhos Tutelares em dar conhecimento dos casos de faltas injustificadas e evasão escolar.

O ensino fundamental deve ser presencial, sendo o ensino a distância utilizada como complementação da aprendizagem ou em situaçóes emergenciais.

E permitida ao município a atuação em outros níveis de ensino médio e superior somente quando estiverem atendidas plenamente as necessidades de sua área de competência e com recursos acima dos percentuais mínimos vinculados pela Constituição Federal a manutenção e ao desenvolvimento do ensino.

\subsection{As políticas Públicas específicas para a Educação Rural}

A necessidade de políticas públicas específicas para o campo vem nos últimos anos norteando o debate que se estabelece acerca da educação para o meio rural.

A seguir destacaremos alguns pontos fundamentais que têm sido evidenciados pelo movimento em defesa da educação do campo: a inclusão das demandas do campo na agenda pública do país e a construção de políticas públicas específicas para os povos do campo. Nesse sentido, cumpre-nos enfatizar que o conceito de políticas públicas será compreendido como o conjunto de açóes resultantes do processo de institucionalização das demandas coletivas, constituídas pela interação entre Estado - sociedade. (Texto Base da I Conferência Por uma Educação do Campo, 1999, p. 57)

Um aspecto fundamental que não pode ficar ausente das discussões acerca das políticas educacionais para o campo, é o reconhecimento por parte daqueles que elaboram as políticas públicas de que o campo está vivo e em constante movimento.

Nesse sentido, Caldart (p. 41) afirma que a Educação Rural no Brasil é um espaço de tensóes, lutas sociais, organizaçóes e movimentos de trabalhadores e trabalhadoras da terra que estão mudando o jeito da sociedade olhar para o campo e seus sujeitos. Esse movimento percebe que é a escola que deve a ele se ajustar, em sua forma e conteúdo, aos sujeitos que dela necessitam; é a escola que deve ir ao encontro dos educandos, e não o contrário.

No entanto, ao fazer a defesa da inclusão das demandas do campo na agenda política do país, há que se analisar uma questáo importante evidenciada por Vieira. Segundo a autora, nos últimos anos está sendo construída e materializada uma "agenda internacional" para a educação. Para iniciar as reflexôes a esse respeito vamos nos situar no modelo econômico adotado, embora de maneira não exaustiva, para entender o que quer dizer "agenda internacional para a educação" 
Nos últimos anos, devemos reconhecer que nossa sociedade passou/passa por profundas transformaçóes em todos os setores. Segundo a literatura, esses acontecimentos estão diretamente relacionados com a reestruturação produtiva do sistema capitalista que ao final do século XX promoveu profundas mudanças, tendo como enfoque principal "reformas" em todos os setores, para atender as demandas do mercado. Lima e Lima (2006, p. 03) pontuam que "o capital, para fazer face a sua crise, utiliza-se de um conjunto de estratégias entre as quais se incluem a reforma do estado, a reestruturação da produção e a crescente internacionalização da economia”

Ao longo dos anos, as políticas educacionais têm sido direcionadas para atender a demanda do sistema produtivo, seguindo assim na contramáo de um processo educativo realmente inclusivo. Isso nos leva a síntese de que a educação tem servido a diferentes interesses.

Nesse sentido, é urgente e necessário, como evidencia Mészarós (2005), "tecer alternativas para que a educação possa transpor os limites do capital”. Assim, para esse autor, uma das funçôes principais da educação formal em nossas sociedades é produzir tanta conformidade, ou, "consenso", quanto for capaz. Para ele, as soluçôes no âmbito da educação, para romper com a lógica do capital, não devem ser formais, devem ser essenciais e devem abarcar a totalidade das práticas educacionais da sociedade.

Nesse sentido, as políticas sociais para o Brasil e para a Amazônia devem contemplar a diversidade cultural e social existente, reconhecendo que no campo habitam diversos sujeitos com diferentes especificidades e modos de vida, pois como nos destaca Hage (2005, p. 61):

[...] a Amazônia apresenta como uma de suas características fundamentais a "heterogeneidade" que se expressa de forma bastante significativa no cotidiano da vida, do trabalho e das relaçóes sociais, culturais e educacionais dos sujeitos que nela habitam, heterogeneidade essa, que deve ser valorizada e incorporada nos processos e espaços de elaboração e implementação de políticas e propostas educacionais para a regiáo.

O autor (2005a) destaca que a heterogeneidade, os saberes e as experiências presentes nas práticas sociais locais têm sido ignorados nas proposições das políticas e propostas educacionais para a região. Nesse contexto, torna-se urgente a defesa de uma educação não direcionada para o mercado educativo, mas para o campo no Brasil, em específico, o campo na Amazônia. Em um contexto onde as políticas sociais têm sido direcionadas por organismos internacionais fica difícil essa conversão, mas não impossível.

\subsection{Alfabetização Rural no Brasil}

Segundo Simôes (2011), "desse modo, existe registro do conceito de educação rural desde 1989, com a proclamação da república, época em que o governo cria a pasta da 'Agricultura, Comércio e Indústria' para atender os estudantes das áreas rurais...”, mas somente em meados de 1917, com o aumento do ciclo de migração da zona rural para a urbana, começa a se falar na importância de levar maior qualidade de ensino aos ambientes mais rurais do país, visto que estas migraçôes traziam para as áreas urbanas pessoas com baixa escolaridade, muitas vezes analfabetas, o que diminuíam e muito o crescimento do país, pois evidenciavam a falta de educação básica nas zonas mais interioranas do Brasil.

Logo, com o que foi relatado por Simóes, pode se observar que a educação rural se 
fez necessário, para que pudesse evitar o grande nível de migraçáo que estava ocorrendo no país, que afetava o crescimento do Brasil e que ainda, segundo a autora Luane Machado "a escola rural passa a ser planejada sobremaneira nos espaços urbanos e aplicada na área rural...” (MACHADO, p. 3).

A LDB ( Lei das Diretrizes e Bases da Educação) garante em seu artigo 28, que a educação em escolas rurais passe a ter conteúdos e disciplinas voltadas a melhoria de vida do homem do campo, visando o crescimento das zonas rurais e a diminuição da transição entre as zonas, porém mesmo com todas essas mudanças percebemos que as problemáticas encontradas ainda são muitas, que a desigualdade no ensino é extrema e que por falta de investimentos, o acesso à educação neste ambientes ainda deixa muito a desejar, o que ainda influi muito no crescimento econômico-social do Brasil.

Art. 28. Na oferta de educação básica para a população rural, os sistemas de ensino promoverão as adaptações necessárias à sua adequação às peculiaridades da vida rural e de cada região, especialmente:

I - conteúdos curriculares e metodologias apropriadas às reais necessidades e interesses dos alunos da zona rural;

II - organização escolar própria, incluindo adequação do calendário escolar às fases do ciclo agrícola e às condiçóes climáticas;

III - adequação à natureza do trabalho na zona rural. (BRASIL, 1996).

A falta de recursos financeiros e pedagógicos, as dificuldades com transporte escolar, a falta de acesso a literatura, as limitaçôes tecnológicas e a alta precariedade na estrutura física e de ensino nestas zonas, são apenas algumas problemáticas que dificultam o acesso desses educandos a melhores condiçóes de ensino e consequentemente a dificuldade na realização de pesquisas e trabalhos científicos nas áreas dentro ou fora do contexto rural.

\section{Consideraçóes finais}

Atualmente vivemos tempos em que o nacionalismo volta a ter destaque em suas manifestaçôes populares, demonstradas em atos democráticos e, às vezes, nem tanto assim. Reflexo de toda a educação implementada até aqui, inclusive, é base para novos trabalhos de aperfeiçoamento de diretrizes, de práticas pedagógicas mais consistentes sob o amparo de políticas públicas educacionais mais inclusivas, na prática.

Visando a implementação de políticas públicas educacionais, o Brasil tem que procurar ampliar os direitos á educação, e mais do que isso botá-los em prática e fazer com que a sociedade tenha conhecimento dos seus devidos direitos, sendo assim, incluir a sociedade nessa busca de melhor atender as necessidades obtidas no meio educacional.

Desta forma, a conexão entre a legislação e as ações das políticas públicas para a educação é realizada por diretrizes que definem o caminho para o planejamento e a realização de açóes. Sendo assim, essas açôes se baseiam principalmente na inclusiva e no ensino de qualidade para que assim a construção do conhecimento seja uma forma de inserir o sujeito no meio social. 


\section{Referências}

BRASIL. Constituição 88. Constituição da República Federativa do Brasil. Brasília, DF: Senado Federal. Acesso em julho. de 2021.

BRASIL. $L D B$ - Lei no 9.394, de 20 de dezembro de 1996. Estabelece as Diretrizes e Bases da Educação Nacional. Brasília: Diário Oficial da União, 1996. Disponível em: http://www. planalto.gov.br/ccivil_03/leis/19394.htm. Acesso em julho de 2021.

CALDART, Roseli Salete. (Orgs). Por uma Educação Básica do Campo. Coleção por uma educação básica no campo. n. 03, Brasília: DF. Articulação Nacional Por Uma Educação do Campo, 2000.

GIRON, Graziela Rossetto. Políticas públicas, educação e neoliberalismo: o que isso tem a ver com a cidadania. Revista de Educação. Campinas. n. 24. jun. 2008.

HAGE, Salomão Mufarrej. Classes Multisseriadas: desafios da educação rural no Estado do Pará/Região Amazônica. In: HAGE, Salomão Mufarrej (Org). Educação do Campo na Amazônia: Retratos e realidades das Escolas Multisseriadas no Pará. Belém: Gutemberg, 2005.

LIMA, K; LIMA, S. Divida pública e educaçâo superior brasileira: financiamento público como garantia de direitos sociais e de democracia. Disponível em www.jubileubrasil.org.br/artigo/ artigoeducação.doc. Acesso em julho de 2021.

MÉSZÁROS, István. A educação para além do capital. TAVARES, Isa (Trad). São Paulo: Boitempo, 2005.

VIEIRA, Sofia Lerche. Políticas Internacionais e Educação - Cooperação ou intervenção? In: DOURADO, Luís Fernandes; PARO, Vitor Henrique (Orgs). Políticas Públicas \& Educação Básica. São Paulo: Xamã, 2001. 